\title{
Modelling the effect of initial density on soil-water characteristic curves
}

\author{
A.-N. ZHOU*, D. SHENG† and J. P. CARTER $\dagger$
}

\begin{abstract}
This paper presents a simple approach to quantify the effect of initial soil density on the soil-water characteristic curve (SWCC) of unsaturated soils. This approach is based on an incremental relationship between the degree of saturation and the initial void ratio, which satisfies the intrinsic constraints for three-phase porous materials. The incremental relationship can be incorporated into existing SWCC equations to model the water retention behaviour for deformable soils. Only one additional parameter is introduced, which can be conveniently calibrated by way of conventional water retention tests. The SWCCs for the same soil at different initial void ratios can be found using the proposed approach. The proposed approach is validated against experimental data from drying tests for both compacted and reconstituted soils.
\end{abstract}

KEYWORDS: constitutive relations; partial saturation; suction; water flow
Cette communication présente une simple méthode pour quantifier l'effet de la densité initiale du sol sur la courbe caractéristique sol-eau (SWCC) de sols non saturés. Cette approche est basée sur un rapport incrémentiel entre le degré de saturation et l'indice de vide initial, répondant aux contraintes intrinsèques des matières poreuses triphasées. Le rapport incrémentiel peut être incorporé dans des équations SWCC existantes, afin de modéliser le comportement de rétention de l'eau pour des sols déformables. On n'introduit qu'un seul paramètre supplémentaire, que l'on peut calibrer de façon pratique par le biais d'essais de rétention d'eau traditionnels. Il est possible d'établir, avec la méthode proposée, les SWCC pour le même sol, avec différents indices de vide. On valide la méthode proposée en la rapprochant avec des données expérimentales provenant d'essais de séchage pour sols compactés et sols reconstitués.

\section{INTRODUCTION}

The soil-water characteristic curve (SWCC) is defined as the relationship between the degree of saturation, $S_{\mathrm{r}}$ (or the volumetric water content, $\theta$ ) and the matric suction, $s$ (or soil-water potential, $\psi$ ). It is usually obtained by drying or wetting a soil sample under constant stress while monitoring the changes of water content in the soil. In the paper, the term 'stress' is used to designate 'net stress' for the purpose of simplicity. The SWCC is also called the soil moisture characteristic curve or the soil-water retention curve. The SWCC of a soil can usually give an indication of the hydraulic properties of the soil, and has various applications in soil physics and soil mechanics. The SWCC is widely used to predict hydraulic conductivity, soil-water storage, field capacity and soil aggregate stability in agricultural engineering (Brady, 1999). It is also commonly employed in estimating the shear strength, stress-strain relationships and permeability of unsaturated soils (Mualem, 1976; Fredlund et al., 1994; Fredlund et al., 1996; Wheeler, 1996; Assouline, 2001). The study of the SWCC goes back to the beginning of the twentieth century. According to Brady (1999), Buckingham was perhaps the first to propose an SWCC equation, in 1907. From then on, many equations have been proposed to model SWCCs (e.g. Gardner, 1956; Brooks \& Corey, 1964; Mualem, 1976; van Genuchten, 1980; Fredlund \& Xing, 1994; Aubertin et al., 2003; Li, 2005). Some of these equations are based on functional regression of experimental data, whereas others are based on empirical correlation with other soil properties, such as particle or pore size distribution, porosity and specific surface area (Arya \& Paris, 1981; Aubertin et al., 2003;

Manuscript received 10 November 2010; revised manuscript accepted 13 October 2011. Published online ahead of print 9 June 2012.

Discussion on this paper closes on 1 January 2013, for further details see $\mathrm{p}$. ii.

* School of Civil, Environmental and Chemical Engineering, Royal Melbourne Institute of Technology (RMIT), Australia.

$\dagger$ Centre for Geotechnical and Materials Modelling, the University of Newcastle, Australia.
Haverkamp et al., 2005; Zhang \& Chen, 2005; Wang et al., 2008). It has been recognised that SWCCs are affected by many factors, such as the pore size and pore shape distribution, specific surface area, particle-size distribution, chemophysical properties of the soil phases, soil density and even temperature (Burger \& Shackelford, 2001a, 2001b; Romero et al., 2001; Chateau \& Viet, 2010). However, it is also realised that most existing SWCC equations are phenomenological in nature. In this regard, it is anticipated or hoped that the effects of the above-mentioned factors on SWCCs can be incorporated into the parameters used in these equations. In other words, samples with, for example, different particle-size distributions are effectively modelled as different soils using different parameter values.

One specific factor that affects the SWCC is the density or porosity of the soil. The density or porosity of one soil can change considerably, depending on the stress and suction states as well as the stress and suction history of the soil. In principle, it is difficult to justify treating samples of a given soil at different densities as entirely different soils for the purpose of modelling. On the other hand, the SWCC is characteristic for a given soil only at a specific density and specific stress level. As stated by Assouline (2006), a change of soil density can lead to a significant change of the SWCC, and such a change in soil density is a common feature of natural soils. The issue of the effect of soil density on the hydraulic properties of a soil was perhaps first raised by Croney \& Coleman (1954) and then by Laliberte et al. (1966). Recently, the study of the effect of density on the hydraulic properties of unsaturated soils has attracted much attention (Ng \& Pang, 2000; Gallipoli et al., 2003; Wheeler et al., 2003; Sun et al., 2007; Khalili et al., 2008; Miller et al., 2008; Nuth \& Laloui, 2008; Masin, 2010; Sheng \& Zhou, 2011). In the literature, various approaches have been proposed to model the effect of soil density on SWCCs. For example, Gallipoli et al. (2003) suggested including a function of specific volume $(v)$ in the SWCC equation proposed by van Genuchten (1980). Sun et al. (2008) proposed a hydraulic model whereby a change in the degree of saturation, $S_{\mathrm{r}}$, can be caused by a change in matric 
suction or a change in soil volume, $v$. Masin (2010) proposed a hydraulic model that can predict the dependence of $S_{\mathrm{r}}$ on the void ratio $(e)$ using the effective stress principle. Tarantino (2009) proposed an SWCC equation for deformable soils based on an empirical power function of the water ratio, $e_{\mathrm{w}}$. This model is very similar to the model by Gallipoli et al. (2003), but has one parameter fewer than Gallipoli's model. Very recently, Sheng \& Zhou (2011) proposed an incremental relationship between $S_{\mathrm{r}}$ and $e$ by realising that the SWCC is obtained under constant stress instead of constant volume.

All the above-mentioned models are intended to simulate the relationship between $S_{\mathrm{r}}$ and soil density ( $e$ or $\left.v\right)$ under an arbitrary suction level, which can be generalised by the equation

$$
\frac{\mathrm{d} S_{\mathrm{r}}(s)}{\mathrm{d} e}=g(s, e)
$$

where $g$ is a general function.

In practice, it is sometimes necessary to predict the SWCCs of a given soil at different initial densities with very limited laboratory data, since the conventional water retention test is a cumbersome and time-consuming procedure. It is generally difficult to use equation (1) to predict the effect of initial density on SWCCs directly, because it uses the current void ratio, which changes with suction. The current void ratio can be linked to the initial void ratio through a volume-change equation that defines the relationship between void ratio and suction. This volume-suction relationship usually involves the compressibility and the stress history of the soil. At least three additional parameters would therefore be needed to quantify the effect of initial density on SWCCs: the elastic compressibility, the elastoplastic compressibility and the yield suction. Some models also use an empirical volume-shrinkage curve together with equation (1) to quantify the effect of initial density on the SWCC. One of the simplest models in this group is perhaps due to Mbonimpa et al. (2006), and yet it requires three additional parameters to be specified.

In other models, the shift of SWCCs with the variation of the initial density is realised by way of a density-dependent air entry value (e.g. Huang et al., 1998; Nuth \& Laloui, 2008). This is a simple and effective approach. Nonetheless, such an approach can be applied only to SWCC equations where the air entry value is explicitly used, such as in Brooks \& Corey (1964). In addition, some important intrinsic relations (see the section below on 'Constraints between degree of saturation and initial void ratio') for three-phase mixtures may not necessarily be satisfied.

This paper proposes a very simple method to quantify the effect of initial density on SWCCs. The proposed method is based on deformation constraints for a three-phase mixture (pore air, pore water and solid soil particles) as well as the difference between macropore water and micropore water. This new method can be applied to any existing SWCC equation for soil with monomodal, bimodal or multimodal pore-size distributions. There is only one new parameter introduced, and this new parameter can be conveniently calibrated by experimental results. The predictions of the proposed method are compared with several sets of experimental data available in the literature.

The proposed method can also be applied to quantify the effect of initial density on unsaturated shear strength and unsaturated permeability. The SWCC is commonly adopted to predict the shear strength (Fredlund et al., 1996; Vanapalli et al., 1996; Toll \& Ong, 2003) and permeability (Mualem, 1976; Fredlund et al., 1994) of unsaturated soils. In terms of the shear strength equation for unsaturated soils, the suction friction angle $\left(\phi^{\mathrm{b}}\right)$ or the effective stress variable $(\chi)$ is usually assumed to be related to the SWCC equation. Similarly, the permeability function is usually fully determined once the SWCC equation is known. In such cases the density-dependence of shear strength and permeability can be readily derived from the density dependence of the SWCC.

\section{MODELLING THE EFFECT OF INITIAL DENSITY ON SWCCs}

Macroscopic/microscopic degrees of saturation and effective degree of saturation

As pointed out by Romero et al. (1999), there are two categories of pore in clayey soils: macroscopic pores, where capillary effects are the dominant phenomenon; and microscopic pores, where water is attached to the solid by physicochemical bonds. These two groups of pores suggest that the degree of saturation could also be separated into two components (Alonso et al., 2010): a macroscopic degree of saturation, $S_{\mathrm{r}}^{\mathrm{M}}$, which describes the occupation of water in the macropores; and a microscopic degree of saturation, $S_{\mathrm{r}}^{\mathrm{m}}$, which concerns the water in the micropores. Following Alonso et al. (2010), the degree of saturation can be written as

$$
S_{\mathrm{r}}=S_{\mathrm{r}}^{\mathrm{m}}+S_{\mathrm{r}}^{\mathrm{M}}
$$

Alonso et al. (2010) suggested that $S_{\mathrm{r}}^{\mathrm{m}}$ can be approximately considered as a constant, irrespective of the applied suction or mechanical load. Here, $S_{\mathrm{r}}^{\mathrm{m}}$ is assumed equal to the residual degree of saturation, $S_{\mathrm{r}}^{\text {res }}$

$$
S_{\mathrm{r}}^{\mathrm{m}}=S_{\mathrm{r}}^{\mathrm{res}}
$$

The effective degree of saturation, $S_{\mathrm{e}}$, can be defined as

$$
S_{\mathrm{e}}=\frac{S_{\mathrm{r}}-S_{\mathrm{r}}^{\mathrm{res}}}{1-S_{\mathrm{r}}^{\mathrm{res}}}
$$

Combining equations (2), (3) and (4) together, $S_{\mathrm{r}}^{\mathrm{M}}$ can be rewritten by way of $S_{\mathrm{r}}^{\text {res }}$ and $S_{\mathrm{e}}$ as

$$
S_{\mathrm{r}}^{\mathrm{M}}=S_{\mathrm{e}}\left(1-S_{\mathrm{r}}^{\mathrm{res}}\right)
$$

The change of the initial density is thus assumed to affect only the macroscopic degree of saturation. The microscopic and residual degrees of saturation are assumed to be independent of the initial density.

Constraints between degree of saturation and initial void ratio An unsaturated soil is a mixture of water, air and solid mineral particles, where the pore water is further split into two parts: water in macropores, and water in micropores. It is possible to show that there are certain intrinsic constraints on the relationship between the degree of saturation and the void ratio. For example, when a soil is fully saturated $\left(S_{\mathrm{r}}=1\right)$, the change of volume or density does not cause any change of degree of saturation. Furthermore, when a soil has lost all the water in the macropores (i.e. $S_{\mathrm{r}}^{\mathrm{M}}=0$ ), the degree of saturation remains constant, and becomes independent of further volume change.

To investigate the intrinsic relationship between void ratio and degree of saturation, a conceptual element of a threephase soil volume is illustrated in Fig. 1(a). Let $V_{\mathrm{a}}, V_{\mathrm{w}}^{\mathrm{m}}, V_{\mathrm{w}}^{\mathrm{M}}$ and $V_{\mathrm{s}}$ be the volumes of pore air, micropore water, macropore water and solid particles respectively. Let $V_{\mathrm{w}}$ $\left(=V_{\mathrm{w}}^{\mathrm{m}}+V_{\mathrm{w}}^{\mathrm{M}}\right)$ be the volume of pore water, $V_{\mathrm{v}}\left(=V_{\mathrm{a}}+V_{\mathrm{w}}\right)$ be the volume of voids, and $V\left(=V_{\mathrm{a}}+V_{\mathrm{w}}+V_{\mathrm{s}}\right)$ be the total volume of the soil.

The void ratio $e$, degree of saturation $S_{\mathrm{r}}$, microscopic 


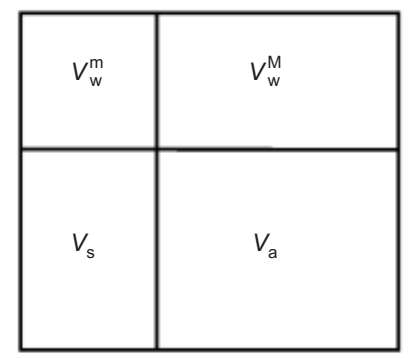

(a)

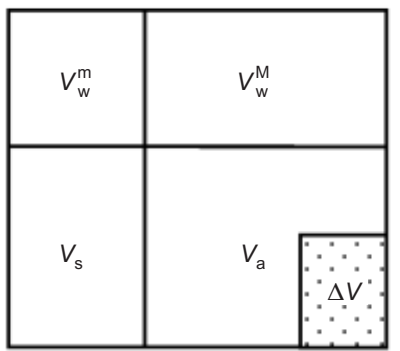

(c)

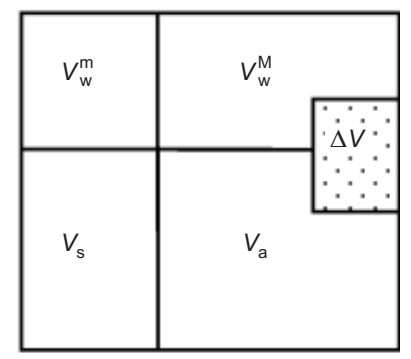

(b)

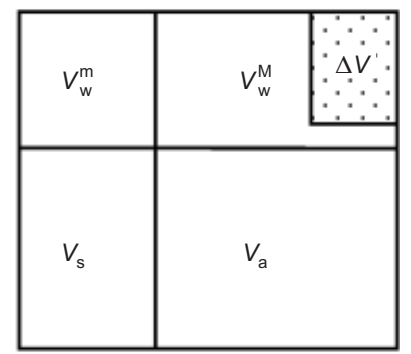

(d)
Fig. 1. (a) Conceptual element of an unsaturated soil; (b)-(d) possible volume changes in the conceptual element

degree of saturation $S_{\mathrm{r}}^{\mathrm{m}}$ and macroscopic degree of saturation $S_{\mathrm{r}}^{\mathrm{M}}$ are defined respectively as

$$
\begin{aligned}
& e=\frac{V_{\mathrm{v}}}{V_{\mathrm{s}}} \\
& S_{\mathrm{r}}=\frac{V_{\mathrm{w}}}{V_{\mathrm{v}}} \\
& S_{\mathrm{r}}^{\mathrm{m}}=\frac{V_{\mathrm{w}}^{\mathrm{m}}}{V_{\mathrm{v}}} \\
& S_{\mathrm{r}}^{\mathrm{M}}=\frac{V_{\mathrm{w}}^{\mathrm{M}}}{V_{\mathrm{v}}}
\end{aligned}
$$

If the element undergoes a volume change $\Delta V$ under constant suction, then the volumes of macropore water and pore air will change, whereas the volumes of solid particles and micropore water are usually assumed to be constant (see Fig. 1(b)). If it is assumed that the volume change of macropore water is $\xi \Delta V$; the volume change of pore air is then $(1-\xi) \Delta V$, with $0 \leqslant \xi \leqslant 1$. For $\xi=0$, the total volume change is equal to the volume change of pore air, which corresponds to the case of undrained compression (Fig. $1(\mathrm{c}))$. The other extreme case is $\xi=1$, where the total volume change is equal to the volume change of macropore water. The case $\xi=1$ occurs when the soil is fully saturated. Under more general circumstances, we have $0 \leqslant \xi \leqslant 1$. Therefore the change in void ratio $\Delta e$, macroscopic degree of saturation $\Delta S_{\mathrm{r}}^{\mathrm{M}}$, and microscopic degree of saturation $\Delta S_{\mathrm{r}}^{\mathrm{m}}$ can be expressed as

$$
\begin{aligned}
& \Delta e=\frac{-\Delta V}{V_{\mathrm{s}}} \\
& \Delta S_{\mathrm{r}}^{\mathrm{M}}=\frac{V_{\mathrm{w}}^{\mathrm{M}}-\xi \Delta V}{V_{\mathrm{v}}-\Delta V}-\frac{V_{\mathrm{w}}^{\mathrm{M}}}{V_{\mathrm{v}}} \\
& \Delta S_{\mathrm{r}}^{\mathrm{m}}=0
\end{aligned}
$$

$$
\begin{aligned}
\Delta S_{\mathrm{r}}^{\mathrm{M}} & =\frac{V_{\mathrm{w}}^{\mathrm{M}}+\xi \Delta e V_{\mathrm{s}}}{V_{\mathrm{v}}+\Delta e V_{\mathrm{s}}}-S_{\mathrm{r}}^{\mathrm{M}} \\
& \Rightarrow\left(S_{\mathrm{r}}^{\mathrm{M}}+\Delta S_{\mathrm{r}}^{\mathrm{M}}\right)(e+\Delta e)=e S_{\mathrm{r}}^{\mathrm{M}}+\xi \Delta e
\end{aligned}
$$

Expanding equation (8) using Leibniz's notation, and omitting the second-order infinitesimal term $\left(\Delta S_{\mathrm{r}}^{\mathrm{M}} \Delta e\right)$, leads to

$$
\frac{\mathrm{d} S_{\mathrm{r}}^{\mathrm{M}}}{\mathrm{d} e}=\frac{\xi-S_{\mathrm{r}}^{\mathrm{M}}}{e}
$$

Since $0 \leqslant \xi \leqslant 1$, the intrinsic constraint between the variations of $S_{\mathrm{r}}^{\mathrm{M}}$ and $e$ is

$$
-\frac{S_{\mathrm{r}}^{\mathrm{M}}}{e} \leqslant \frac{\mathrm{d} S_{\mathrm{r}}^{\mathrm{M}}}{\mathrm{d} e} \leqslant \frac{1-S_{\mathrm{r}}^{\mathrm{M}}}{e}
$$

Replacing $S_{\mathrm{r}}^{\mathrm{M}}$ by $S_{\mathrm{e}}$ by way of equation (5), the above equation can be rewritten as

$$
-\frac{S_{\mathrm{e}}}{e} \leqslant \frac{\mathrm{d} S_{\mathrm{e}}}{\mathrm{d} e} \leqslant \frac{1-S_{\mathrm{e}}}{e}
$$

When deriving the above constraint, it is considered fact that the volume change can be caused only by a stress change while the suction is kept constant. In the context of soilwater characteristic curves where the stress is kept constant, the void ratio in the above constraint thus corresponds to the initial void ratio at the start of an SWCC test (i.e. the saturated void ratio for a drying test).

Considering constraint (11) and the discussion above, the following incremental relationship between degree of saturation and initial void ratio is proposed to describe the effect of initial density on SWCC

$$
\frac{\mathrm{d} S_{\mathrm{e}}}{\mathrm{d} e_{\mathrm{i}}}=-\frac{S_{\mathrm{e}}}{e_{\mathrm{i}}}\left(1-S_{\mathrm{e}}\right)^{\xi}
$$

where $e_{\mathrm{i}}$ is the initial void at the start of the SWCC test (or the saturated void ratio for a drying test), and $\zeta$ is a fitting parameter. Equation (12) also satisfies the following basic constraints.

(a) For saturated soil $\left(S_{\mathrm{r}}=1\right)$, a change in soil volume does not lead to any change in degree of saturation, that is, $\mathrm{d} S_{\mathrm{e}}=0$ when $S_{\mathrm{e}}=1$

(b) For unsaturated soil at the residual degree of saturation $\left(S_{\mathrm{r}}=S_{\mathrm{r}}^{\mathrm{res}}\right)$, the degree of saturation remains constant, irrespective of any change in soil volume, that is, $\mathrm{d} S_{\mathrm{e}}=0$ when $S_{\mathrm{e}}=0$.

Equation (12) is not the unique expression that satisfies constraint (11) and the above constraints, but perhaps one of the simplest options. It should be noted that equation (12) is in incremental form, and therefore it only defines the variation of the degree of saturation caused by a variation of initial void ratio. This equation can be solved by integration, and the solution will depend on a reference state (e.g. a reference SWCC, $S_{\mathrm{r}}^{\text {ref }}$, at a reference initial void ratio, $\left.e_{\mathrm{i}}^{\text {ref }}\right)$. Since the shift of the SWCC due to the initial void ratio is governed by such an incremental equation, any SWCC equation can be selected as the reference SWCC. Equation (12) can be integrated numerically for an arbitrary value of $\zeta$. For simplicity, some formula for numerical approximation of definite integrals (such as Simpson's rule) can also be employed to obtain approximate closed-form equations (see the Appendix). In special cases, such as $\zeta=1$ and $\zeta=0.5$, analytical solutions are available, as follows.

$$
\frac{1-S_{\mathrm{e}}}{S_{\mathrm{e}}}=\frac{1-S_{\mathrm{e}}^{\mathrm{ref}}}{S_{\mathrm{e}}^{\mathrm{ref}}} \frac{e_{\mathrm{i}}^{\mathrm{ref}}}{e_{\mathrm{i}}} \quad(\zeta=1)
$$




$$
\frac{1-\sqrt{1-S_{\mathrm{e}}}}{1+\sqrt{1-S_{\mathrm{e}}}}=\frac{e_{\mathrm{i}}^{\mathrm{ref}}}{e_{\mathrm{i}}} \frac{1-\sqrt{1-S_{\mathrm{e}}^{\mathrm{ref}}}}{1+\sqrt{1-S_{\mathrm{e}}^{\mathrm{ref}}}} \quad(\xi=0 \cdot 5)
$$

where

$$
S_{\mathrm{e}}^{\mathrm{ref}}=\frac{S_{\mathrm{r}}^{\mathrm{ref}}-S_{\mathrm{r}}^{\mathrm{res}}}{1-S_{\mathrm{r}}^{\mathrm{res}}}
$$

It is also interesting to compare the proposed equation with the method by Gallipoli et al. (2003), where the van Genuchten equation (van Genuchten, 1980) is modified to take into account the effect of soil density

$$
S_{\mathrm{r}}=\left[\frac{1}{1+\left(\phi e^{\varphi} s\right)^{m}}\right]^{n}
$$

where $m$ and $n$ are the fitting parameters in the original van Genuchten equation, and $\varphi$ and $\phi$ are two soil constants introduced by Gallipoli et al. (2003). Differentiating this equation leads to

$$
\frac{\mathrm{d} S_{\mathrm{r}}}{\mathrm{d} e}=-\varphi m n \frac{S_{\mathrm{r}}\left[1-\left(S_{\mathrm{r}}\right)^{1 / n}\right]}{e}
$$

Equation (17) is indeed very similar to equation (12). The essential difference is the product ( $\varphi m n)$ in equation (17). This product is set to 1 in the proposed model in order to satisfy constraint (11). Gallipoli et al. (2003) incidentally set the product to $1 \cdot 1$ in all their numerical examples. The quantities $\left(1-S_{\mathrm{r}}\right)^{\xi}$ in equation (12) and $1-\left(S_{\mathrm{r}}\right)^{1 / n}$ in equation (17) both represent a number between 0 and 1 , and are mathematically equivalent. Another difference is that Gallipoli et al. (2003) used the current void ratio and the degree of saturation in equation (17) instead of the initial void ratio and the effective degree of saturation respectively.

\section{CALIBRATION AND MODEL PERFORMANCE \\ Model calibration}

The proposed equation (11) involves only one new parameter, $\xi$. This parameter, as will be shown below, varies within a relatively small range, and as a first approximation can be treated as a general constant, irrespective of soil type. For more accurate and flexible predictions $\zeta$ can be treated as a constant specific to a soil type. In such cases, at least two conventional water retention tests must be conducted in order to calibrate the model. One test is used to calibrate all fitting parameters for a reference SWCC $\left(S_{\mathrm{r}}^{\text {ref }}\right)$ at a reference void ratio $\left(e_{i}^{\text {ref }}\right)$. The other test is conducted at a different initial void ratio and is used to calibrate the new fitting parameter $\zeta$. The calibrated model can then be used to find the SWCC at an arbitrary initial void ratio. Experimental results from Romero (1999) for Boom clay (see Fig. 2) with different initial void ratios are employed here to demonstrate the parameter calibration process of the proposed model. The SWCC data with initial void ratio of 0.93 are used to calibrate the reference SWCC equation.

Many SWCC equations exist in the literature (e.g. Gardner, 1956; Brooks \& Corey, 1964; van Genuchten, 1980; Fredlund \& Xing, 1994). Equation (12) can be used with any of these equations. The van Genuchten equation (van Genuchten, 1980) is used here as an example.

$$
S_{\mathrm{r}}^{\mathrm{ref}}=S_{\mathrm{r}}^{\mathrm{res}}+S_{\mathrm{e}}^{\mathrm{ref}}\left(1-S_{\mathrm{r}}^{\mathrm{res}}\right)
$$

with

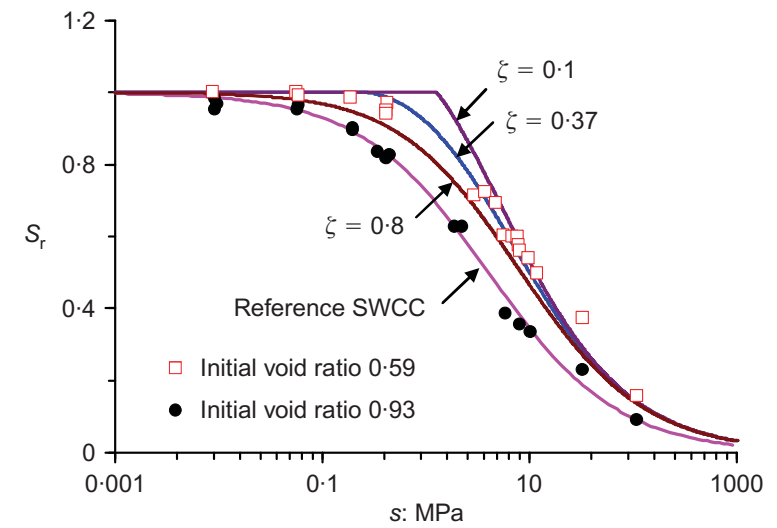

(a)

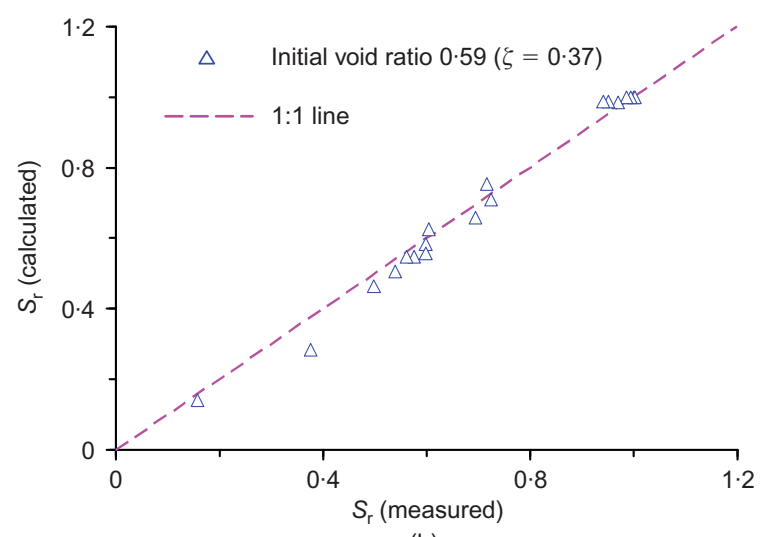

(b)

Fig. 2. Calibration of reference SWCC and new parameter $\xi$ (data after Romero, 1999): (a) calibration curves with different $\zeta$; (b) calculated $S_{\mathrm{r}}$ against measured $S_{\mathrm{r}}(\zeta=0 \cdot 37)$

$$
S_{\mathrm{e}}^{\mathrm{ref}}=\left[1+\left(\frac{s}{a}\right)^{m}\right]^{-n}
$$

where $S_{\mathrm{e}}^{\text {ref }}$ is the effective degree of saturation for the reference SWCC, $a, m$ and $n$ are fitting parameters, $S_{\mathrm{r}}^{\text {res }}$ is the residual degree of saturation, and $S_{\mathrm{r}}^{\mathrm{res}}=\theta_{\mathrm{r}} / \theta_{\mathrm{s}}$, with $\theta_{\mathrm{r}}$ being the residual water content and $\theta_{\mathrm{s}}$ the saturated water content. In van Genuchten's equation no clear threshold value of the matric suction, like the air entry value, can be identified. The fitting parameters for the Boom clay $\left(e_{i}^{\text {ref }}=0.93\right)$ are calibrated as follows: $a=4 \mathrm{MPa}, \quad m=0 \cdot 7, \quad n=1 \cdot 0$, and $S_{\mathrm{r}}^{\text {res }}=0 \cdot 0$. The reference SWCC is plotted in Fig. 2(a). Equation (19) is usually used for the drying curve only, but could be used for the wetting curve as well. Hydraulic hysteresis can also be incorporated conveniently if considered to be important. In this case the main drying curve, the main wetting curve and the scanning curves will all shift with the initial void ratio of the soil according to equation (12). In this paper, hydraulic hysteresis is not considered.

The water retention test results of Boom clay with initial void ratio of 0.59 are used to calibrate the new fitting parameter $\zeta$. Fig. 2(a) shows the calibration curves with different values of $\zeta(=0 \cdot 1,0.37,0.8)$. The simulation gives the best fit to the experimental data when $\zeta$ is set to a value of $0 \cdot 37$. A comparison between the measured and calculated degrees of saturation is shown in Fig. 2(b) for $\xi=0 \cdot 37$, which indicates that the calibration is relatively successful.

\section{Model performance}

Figure 3 shows the predicted SWCCs at different initial void ratios $\left(e_{\mathrm{i}}=0.93,0.73,0.53\right.$ and 0.33$)$ with the fitting 


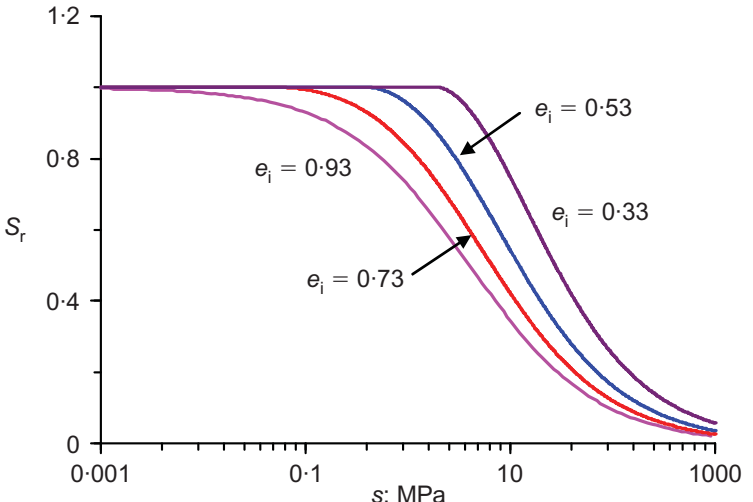

(a)

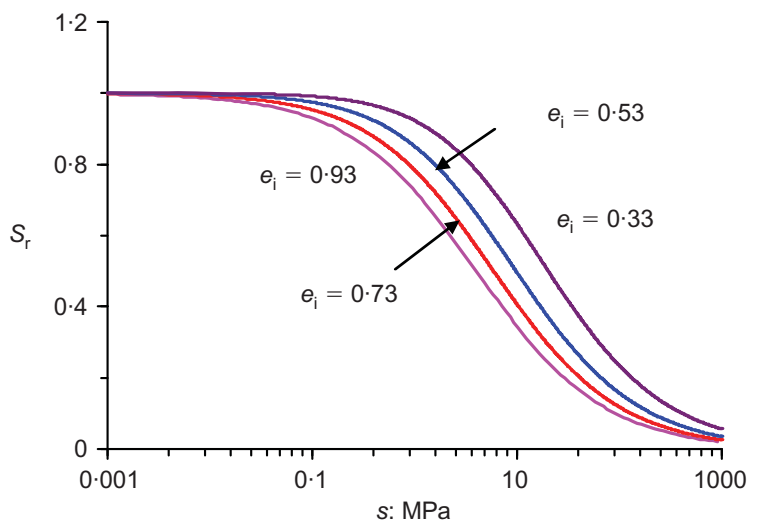

(c)

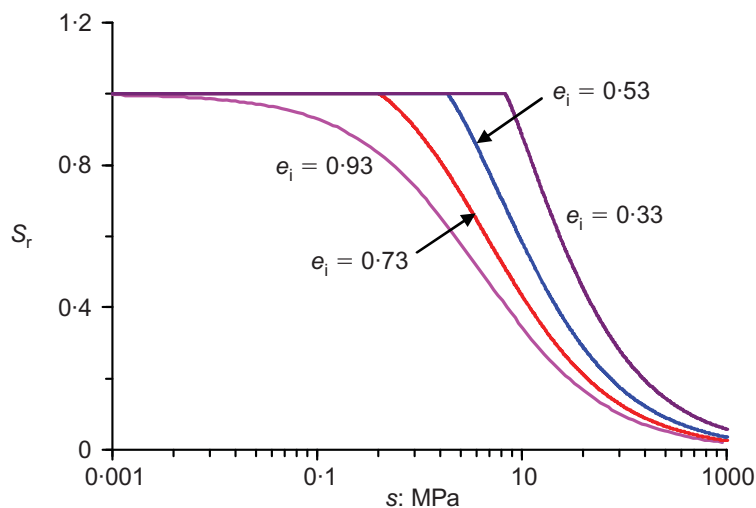

(b)

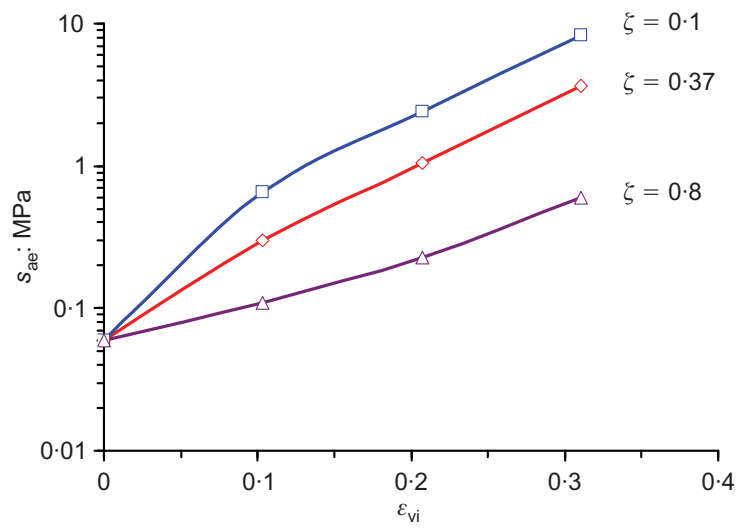

(d)

Fig. 3. Calculated SWCCs for different initial density with different values of fitting parameter $\zeta$ : (a) $\xi=0 \cdot 37$; (b) $\xi=0 \cdot 1$; (c) $\zeta=0 \cdot 8$; (d) calculated relationship between $s_{\mathrm{ae}}$ and $\varepsilon_{\mathrm{vi}}\left(\varepsilon_{\mathrm{vi}}=\left(0 \cdot 93-e_{\mathrm{i}}\right) /(1+0 \cdot 03)\right)$

parameters for Boom clay $(a=4 \mathrm{MPa}, m=0 \cdot 7, n=1 \cdot 0$, and $\left.S_{\mathrm{r}}^{\text {res }}=0 \cdot 0\right)$. In Figs $3(\mathrm{a})-3(\mathrm{c})$, parameter $\xi$ is set to $0 \cdot 37$, 0.1 and 0.8 respectively. The shift of SWCC with initial void ratio is more pronounced as $\zeta$ decreases. The slope of the SWCC also increases as the void ratio decreases, which is similar to the approach proposed by Masin (2010). It is also possible to derive an approximate relationship between the air entry suction and the initial void ratio from Fig. 3. Let the air entry value be defined as the suction where $S_{\mathrm{r}}=95 \%$, and let the volumetric strain, $\varepsilon_{\mathrm{vi}}$, be the percentage change of void ratio from the reference value. The shift of the air entry value with the volumetric strain is plotted in Fig. 3(d) for different values of $\zeta$. It is shown that a decreasing initial void ratio results in an increasing air entry value. The relationship between the air entry value and the volumetric strain is roughly linear on a logarithmic scale when $\zeta=0 \cdot 37$.

Equation (12) is in incremental form, and its solution generally requires numerical integration, which may not always be convenient in engineering practice. However, it also offers great flexibility: it can be used in conjunction with any existing SWCC equation, and any known SWCC can be used as a reference state. All empirical SWCC equations, including those for bimodal or multimodal pore sizes (e.g. Burger \& Shackelford, 2001a; Zhang \& Chen, 2005), can be used with equation (12). Because it is incremental, it can be used for any stress level, as long as the stress levels for the reference state and the desired state remain the same. If the stress level at the desired void ratio is different from the reference state, a coupled hydromechanical approach has to be used (Sheng \& Zhou, 2011).

Figure 4 demonstrates the application of equation (12) to other common SWCC equations (Brooks \& Corey, 1964; Fredlund \& Xing, 1994). Brooks \& Corey's equation is a

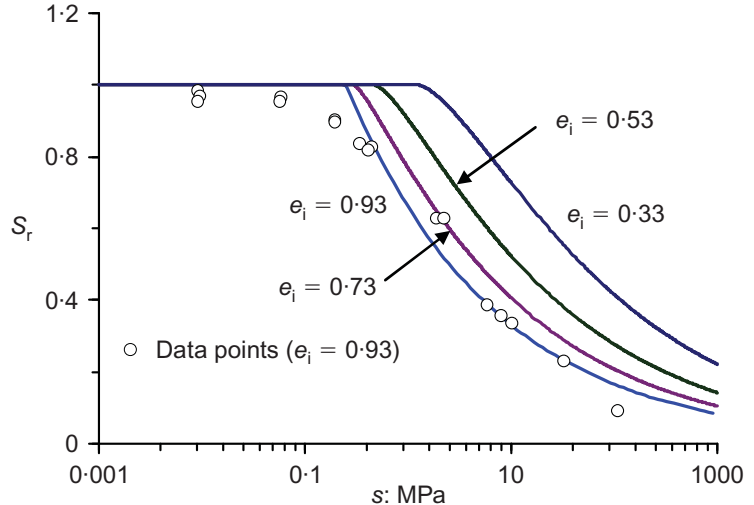

(a)

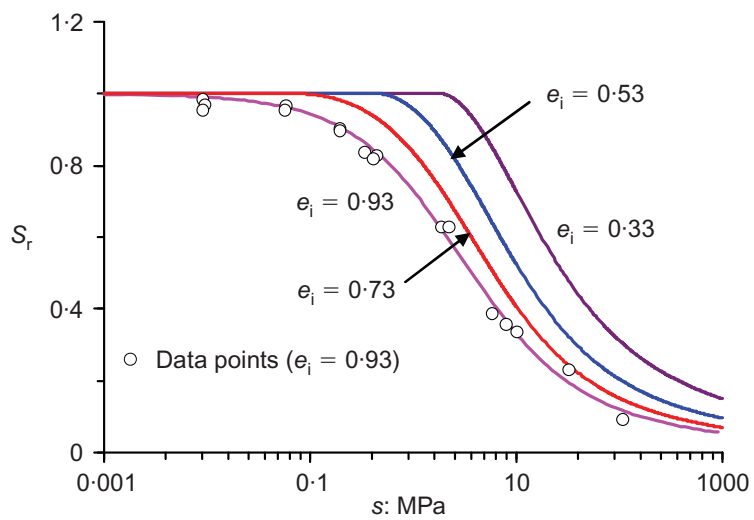

(b)

Fig. 4. Calculated SWCCs for different initial density based on: (a) Brooks \& Corey's equation; (b) Fredlund \& Xing's equation. Data after Romero (1999); $\zeta=0 \cdot 37$ 
typical SWCC equation with an air entry value, and Fredlund \& Xing's equation is also popular in unsaturated soil mechanics. The reference SWCC equations corresponding to Brooks \& Corey's equation and Fredlund \& Xing's equation are shown as follows.

Brooks \& Corey:

$$
S_{\mathrm{e}}^{\mathrm{ref}}= \begin{cases}1 & s \leqslant s_{\mathrm{ae}} \\ \left(s / s_{\mathrm{ae}}\right)^{-\lambda} & s>s_{\mathrm{ae}}\end{cases}
$$

Fredlund \& Xing:

$$
S_{\mathrm{r}}^{\mathrm{ref}}=\frac{1-\left[\ln \left(1+s / s_{\mathrm{re}}\right) / \ln \left(1+10^{6} / s_{\mathrm{re}}\right)\right]}{\left\{\ln \left[2 \cdot 71828+(s / \alpha)^{\beta}\right]\right\}^{\gamma}}
$$

where $\lambda$ is the fitting parameter in Brooks \& Corey's equation; $\alpha, \beta$ and $\gamma$ are three fitting parameters in Fredlund \& Xing's equation; and $s_{\mathrm{re}}$ is the residual suction, which is the suction corresponding to the residual degree of saturation $\left(S_{\mathrm{r}}^{\mathrm{res}}\right)$. For Boom clay, these parameters can be calibrated as follows.

Brooks \& Corey: $s_{\mathrm{ae}}=0.25 \mathrm{MPa}, \lambda=0 \cdot 3$.

Fredlund \& Xing: $\alpha=2.0 \mathrm{MPa}, \quad \beta=0.8, \quad \gamma=1.8$, and $s_{\mathrm{re}}=105 \mathrm{kPa}$.

The fitting parameter $\zeta$ is set to $0 \cdot 37$, as indicated previously. The predicted SWCCs based on Brooks \& Corey's equation and Fredlund \& Xing's equation are shown in Fig. 4 for different initial void ratios $\left(e_{i}=0.93,0.73,0.53\right.$ and $0 \cdot 33)$. In both cases the proposed equation is able to capture the effect of initial void ratio on the SWCC. It can also be seen from Fig. 4(a) that the air entry value is a very inaccurate measure of the experimental suction threshold where the soil becomes unsaturated. Fredlund \& Xing's equation and van Genuchten's equation do not use this threshold suction, and generally represent the experimental data better.

\section{EXPERIMENTAL VALIDATION}

$S_{r}-$ e relationship under constant suction for a compacted soil Suction-controlled oedometer compression tests on a loosely compacted soil of $70 \%$ silt, $20 \%$ kaolin and $10 \%$ London clay were conducted by Jotisankasa (2005). The test results are replotted in the plane of $S_{\mathrm{r}}$ against $1+e$, as shown in Fig. 5. There are two testing series used here: the 7-10 series and the 5-10 series. The 7-10 series includes four datasets (7-10-P, 7-10-V, 7-10-W and 7-10-U) for different suction levels (31.8 MPa, 10.4 MPa, 9.4 MPa and 4.4 MPa respectively). The 5-10 series includes three datasets (5-10-I,

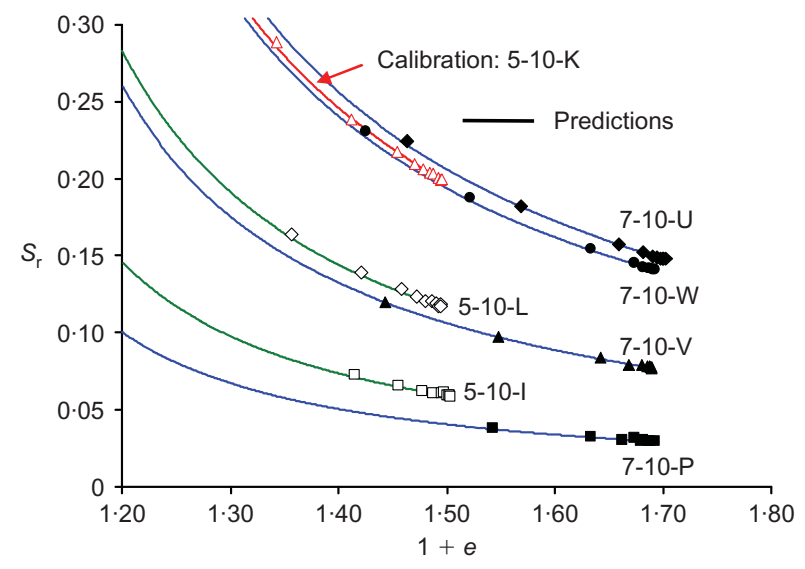

Fig. 5. Calibration and validation of proposed model using suction-controlled oedometer compression data for a compacted soil (data after Jotisankasa, 2005).
5-10-L and 5-10-K) for suction levels at $27 \cdot 3 \mathrm{MPa}, 9 \cdot 7 \mathrm{MPa}$ and $5.4 \mathrm{MPa}$ respectively. The dataset 5-10-K (suction 9.7 $\mathrm{MPa}$ ) is chosen to calibrate parameter $\zeta$ in the proposed model, which gives $\zeta=0 \cdot 1$. This value is then used to predict all other datasets. Since the suction remains constant for each curve in Fig. 5, no SWCC equation is required here, and the only parameter required is $\zeta$. Equation (12) can be used directly to predict the variation of degree of saturation due the variation of stress-induced volume change. In this case, the void ratio $e_{\mathrm{i}}$ in equation (12) is the current void ratio, and it changes because of stress variation in the oedometer tests. Fig. 5 clearly shows that equation (12) predicts the relationship between the degree of saturation and the void ratio very well when the suction is kept constant. Indeed, the experimental data are almost exactly on the predicted $S_{\mathrm{r}}-e$ curves.

\section{Measured and predicted SWCCs of compacted till}

A series of drying tests on a compacted till was reported by Vanapalli et al. (1999). The soil specimens were compacted to different initial void ratios at optimum water content. Figs 6(a)-6(d) show the drying test results for these specimens, with different symbols for different initial void ratios, $e_{\mathrm{i}}$. The test data with initial void ratio of 0.517 were adopted to calibrate the reference SWCC. The fitting parameters for van Genuchten's SWCC equation were calibrated as follows: $a=65 \mathrm{kPa}, m=1 \cdot 0, n=0 \cdot 15$, and $S_{\mathrm{r}}^{\text {res }}=0 \cdot 0$. The test data corresponding to an initial void ratio of 0.514 were employed to calibrate the parameter $\zeta$, which was assigned a value of 0.03 . The remaining two datasets (corresponding to $e_{\mathrm{i}}=0.474$, and $e_{\mathrm{i}}=0.444$ ) were used to validate the proposed approach. The predicted SWCCs were calculated using equation (12), and are shown as solid curves in Fig. 6. The predicted SWCCs in Figs 6(c)-6(d) match the experimental data almost exactly, indicating that the proposed approach captures the effects of initial void ratio on the SWCCs extremely well.

\section{Measured and predicted SWCCs of silty sand}

A series of laboratory experiments was conducted by Huang et al. (1998) to investigate the hydraulic properties of a deformable unsaturated soil. The soil tested was a silty sand from a Saskatchewan Department of Highways borrow pit. This silty sand consisted of $52 \cdot 5 \%$ sand, $37 \cdot 5 \%$ silt and $10 \%$ clay. The specific gravity, liquid limit and plastic limit were $2 \cdot 68,22 \cdot 2 \%$ and $16 \cdot 6 \%$ respectively. The air-dried silty sand was mixed with distilled water to prepare slurried specimens for the experimental programme. Six initially slurried specimens (grouped as PPCT2) were one-dimensionally preconsolidated under different pressures to obtain different initial void ratios for the water retention tests. The test results are replotted in the $S_{\mathrm{e}}-S$ plane together with the predictions of equation (12) in Figs 7(a)-7(f). The water retention test data for an initial void ratio 0.525 were used to calibrate the reference SWCC equation. The fitting parameters were calibrated as follows: $a=65 \mathrm{kPa}, m=1.9$, $n=0 \cdot 5, S_{\mathrm{r}}^{\mathrm{res}}=0 \cdot 0$ and $\zeta=0 \cdot 2$. As shown in Figs $7(\mathrm{c})-7(\mathrm{f})$, the predicted SWCCs agree very well with the experimental SWCCs. The shifting of the SWCC due to changes in the initial density is well portrayed by the proposed approach.

\section{Measured and predicted SWCCs of SI tailings}

Aubertin et al. (1998) investigated the SWCCs for a tailings material denoted as 'SI' with different initial void ratios. This tailings material is a by-product of the milling of ore extracted from underground or open-pit mines, and its 


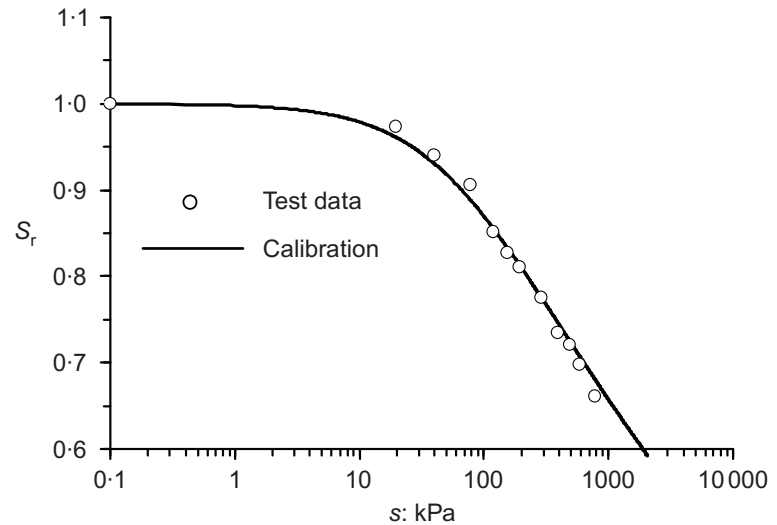

(a)

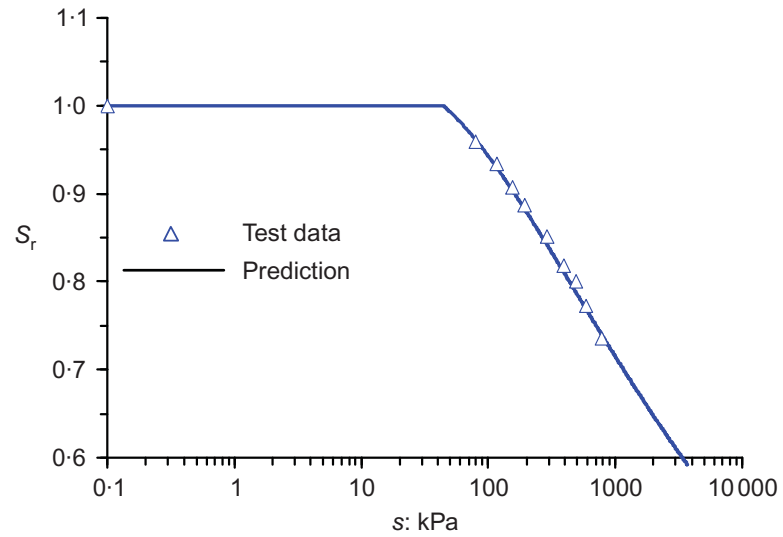

(c)

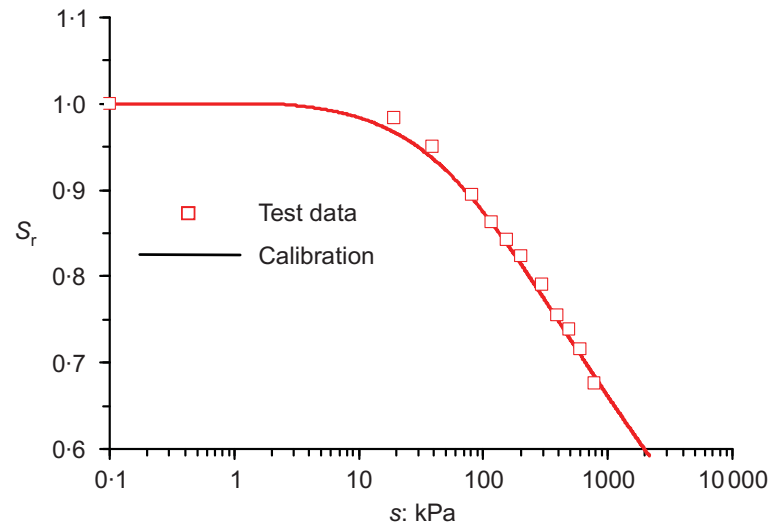

(b)

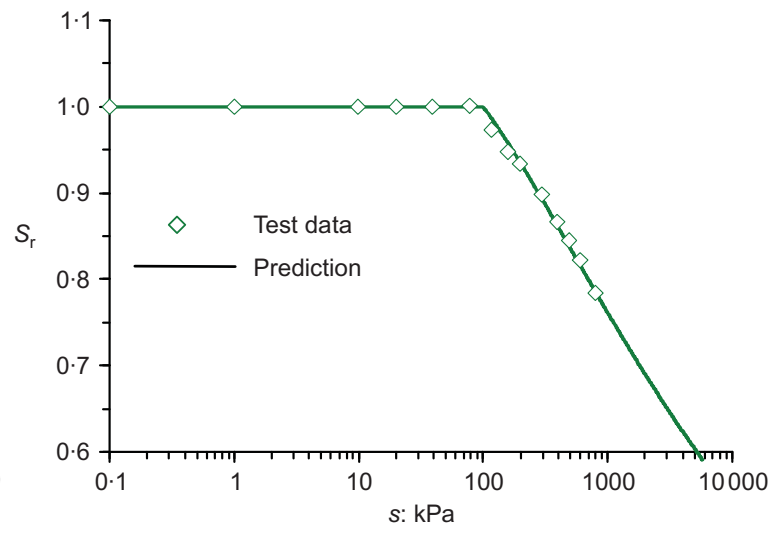

(d)

Fig. 6. Measured and predicted SWCCs for specimens compacted at optimum water content: (a) $e_{\mathrm{i}}=0.517$; (b) $e_{\mathrm{i}}=0.514$; (c) $e_{\mathrm{i}}=0 \cdot 474 ;$ (d) $e_{\mathrm{i}}=0 \cdot 444$. Data after Vanapalli et al. (1999); $a=65 \mathrm{kPa}, m=1 \cdot 0, n=0 \cdot 15, S_{\mathrm{r}}^{\text {res }}=0, \zeta=0 \cdot 03$

grain size is usually equivalent to that of a silty soil. For each water retention test, the remoulded specimens with different initial void ratios $\left(e_{\mathrm{i}}=0.802,0.746,0.695\right)$ were saturated in a triaxial cell first by back-pressure. The test results were originally presented in the space of volumetric water content $\theta$ against suction $s$, but they have been replotted in $S_{\mathrm{r}}-S$ space in Figs $8(\mathrm{a})-8(\mathrm{c})$. As pointed out by Aubertin et al. (1998), the test results for each density were obtained with at least two sets of material samples, which explains some of the data scattering. The test data for the loosest specimen $\left(e_{\mathrm{i}}=0.802\right.$, Fig. 8(a)) were adopted to calibrate the reference SWCC. The fitting parameters for van Genuchten's SWCC equation are: $a=400 \mathrm{cmH}_{2} \mathrm{O}$ $\left(1 \mathrm{cmH}_{2} \mathrm{O}=0.098 \mathrm{kPa}\right), m=1 \cdot 2, n=0.5$ and $S_{\mathrm{r}}^{\text {res }}=0 \cdot 0$. The fitting parameter $\zeta$ was calibrated with the SWCC data at an initial void ratio of 0.746 , and is set to a value of 0.5 . The predicted SWCC in Fig. 8(c) agrees reasonably well with the experimental data. The calculated air entry value $\left(s_{\mathrm{ae}}\right.$ when $S_{\mathrm{r}}=95 \%$ ) for each set is also shown in Fig. 8 to illustrate the influence of initial density on the air entry value.

\section{Measured and predicted SWCCs of reconstituted Barcelona silt}

Tarantino (2009) reported a series of laboratory SWCC tests on reconstituted Barcelona silt with different initial densities. The soil samples were prepared from slurry, and were then consolidated to vertical stresses of $100 \mathrm{kPa}$, $300 \mathrm{kPa}$ or $500 \mathrm{kPa}$ to obtain different initial void ratios. The initial void ratios, $e_{\mathrm{i}}$, at the start of the drying process were $0.62,0.54$ and 0.50 for the samples consolidated to $100 \mathrm{kPa}, 300 \mathrm{kPa}$ and $500 \mathrm{kPa}$ respectively. The fitting parameters for van Genuchten's SWCC equation are: $a=75 \mathrm{kPa}, m=1 \cdot 7, n=0 \cdot 15$ and $S_{\mathrm{r}}^{\text {res }}=0 \cdot 2$. The fitting parameter $\zeta$ was set to $0 \cdot 05$. The experimental data and the predicted SWCCs are shown in Figs 9(a)-9(c). The curves predicted by equation (12) compare very well with the measured data for this reconstituted soil.

\section{Measured and predicted SWCCs of clayey sand}

Very recently, Salager et al. $(2010,2011)$ conducted a series of tests on a clayey sand to investigate the water retention behaviour of a granular soil. The tested soil consisted of $72 \%$ sand, $18 \%$ silt and $10 \%$ clay. The water retention behaviour of the clayey sand compacted at five different void ratios $\left(e_{\mathrm{i}}\right)$ is replotted here in the $S_{\mathrm{r}}-S$ plane, as shown in Figs 10(a)-10(e). The variation of initial void ratios is in the range from 0.44 to 1.01 . The water retention data for the loosest specimen $\left(e_{\mathrm{i}}=1 \cdot 01\right)$ were adopted to calibrate the reference SWCC. The fitting parameters for van Genuchten's SWCC equation are: $a=10 \mathrm{kPa}, m=0 \cdot 6$, $n=0.5$ and $S_{\mathrm{r}}^{\mathrm{res}}=0 \cdot 0$. The parameter $\zeta$ was set to a value of $0 \cdot 1$ according to the SWCC data for $e_{\mathrm{i}}=0 \cdot 86$. The SWCCs predicted by equation (12) are shown in Figs 10(c)10(e). Again, the comparison between the experimental data and predictions is of acceptable accuracy.

\section{Parameter $\zeta$}

The fitting parameter $\zeta$ varies between 0.03 and 0.5 in the analyses described above. This parameter controls the shape of the transitional part of the SWCC around the air entry value. A smaller value of $\zeta$ leads to a sharper transition, as shown in Fig. 3. In addition, the smaller $\xi$ is, the more pronounced is the density effect on the SWCC, particularly 


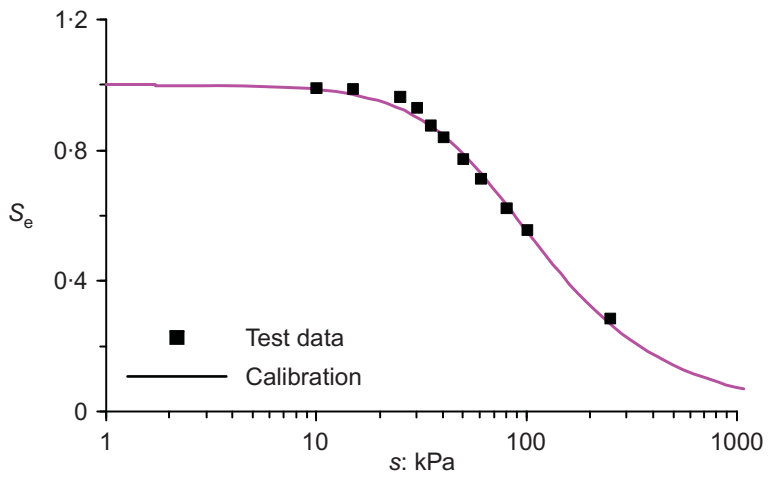

(a)

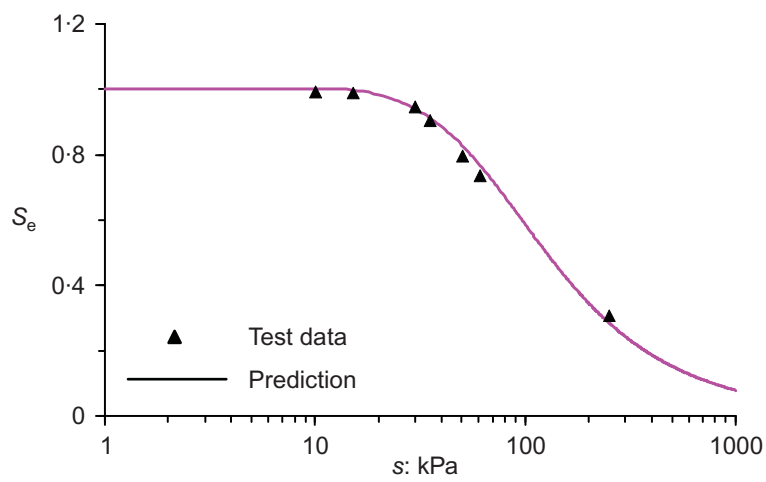

(c)

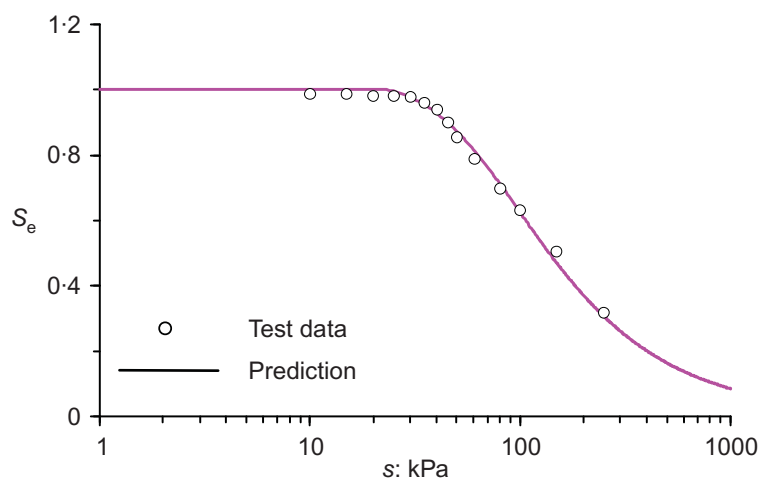

(e)

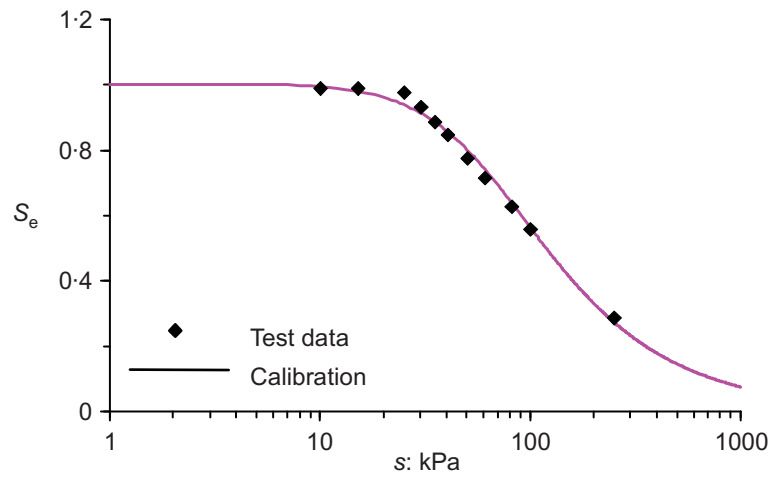

(b)

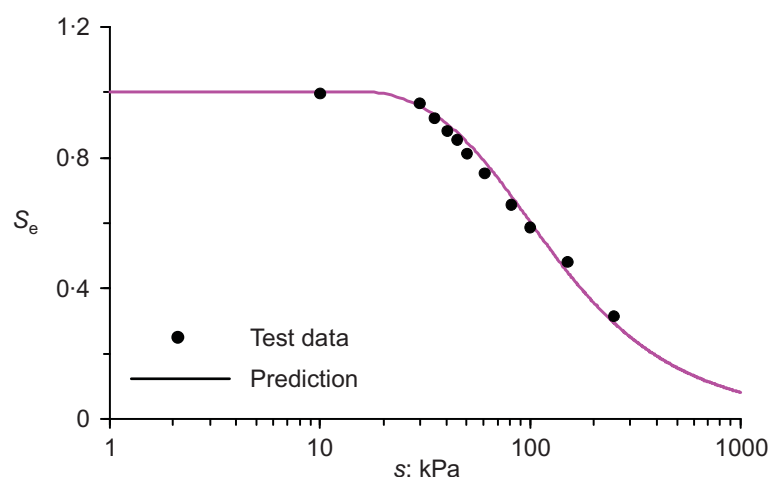

(d)

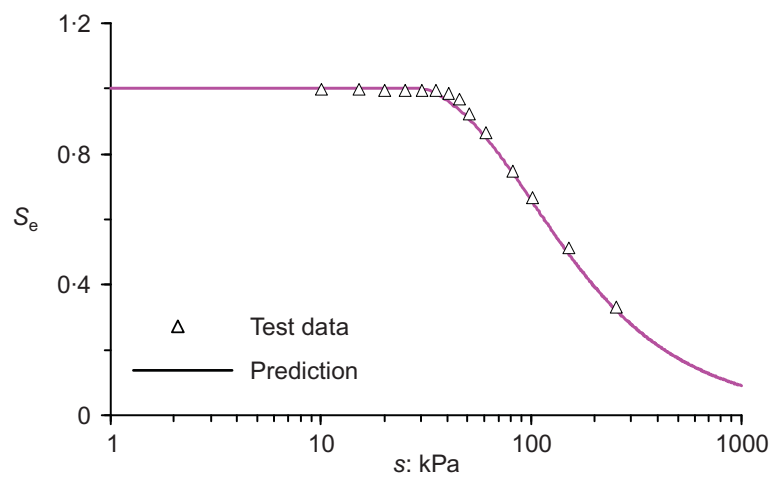

(f)

Fig. 7. Measured and predicted SWCCs for a silty sand with different initial void ratios: (a) $e_{\mathrm{i}}=0.525$; (b) $e_{\mathrm{i}}=0.513$; (c) $e_{\mathrm{i}}=0.490 ;$ (d) $e_{\mathrm{i}}=0 \cdot 474$; (e) $e_{\mathrm{i}}=0.454$; (f) $e_{\mathrm{i}}=0.426$. Data after Huang $e$ t al. (1998); $a=65 \mathrm{kPa}, m=1 \cdot 9, n=0 \cdot 5, S_{\mathrm{r}}^{\mathrm{res}}=0$, $\zeta=0 \cdot 02$

at low suction levels. In the case when there are two known SWCCs at any two different void ratios, $\zeta$ can be calibrated as in the above analyses. If only one SWCC is known, a gross approximation of $\xi$ would be to use an average value of $0 \cdot 2$. Such a gross approximation may affect the accuracy of the predicted SWCC around the air entry value, but does not lead to dramatic differences at higher suctions, as shown in Fig. 2(a).

\section{CONCLUSIONS}

The soil-water characteristic curve, SWCC, plays important roles in calculating soil-water storage, field capacity and soil aggregate stability in agricultural engineering. In geotechnical engineering it is also widely used in predicting collapse or swelling failure of foundations, as well as slope failures due to rainfall. Research shows that this curve is not characteristic, but is influenced by the initial soil density. This paper proposes a simple method that can be combined with existing empirical SWCC equations to describe the effect of initial density on water retention behaviour. This method is based on the intrinsic constraints between the degree of saturation and the void ratio for a three-phase mixture. The difference caused by water in macroscopic pores and microscopic pores is also taken into account in the new model. Only one parameter $(\xi)$ is introduced to describe the effect of initial soil density on the SWCC. The proposed model was validated against a wide range of experimental data available in the literature. It has been shown that the proposed model is able to capture quite well the initial density effect on the SWCC.

\section{APPENDIX}

In engineering applications, it is convenient to have closed-form solutions. For practical purposes, a formula for numerical approximation of definite integrals can be employed to obtain the approximate closed-form solution for equation (12). In this paper, 


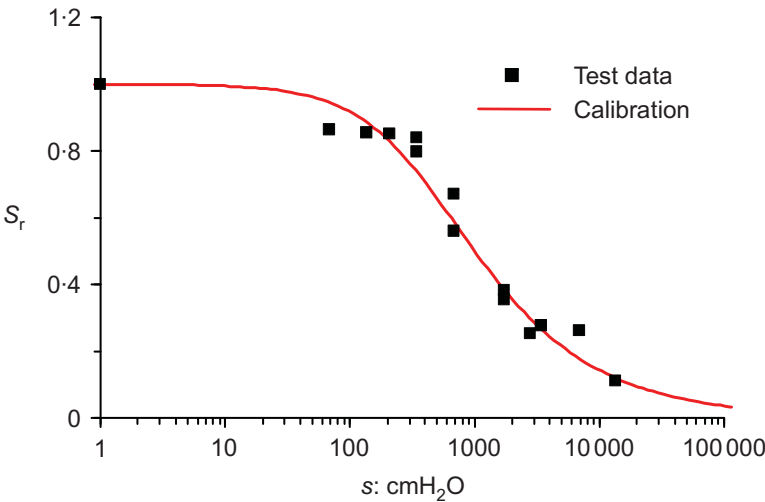

(a)

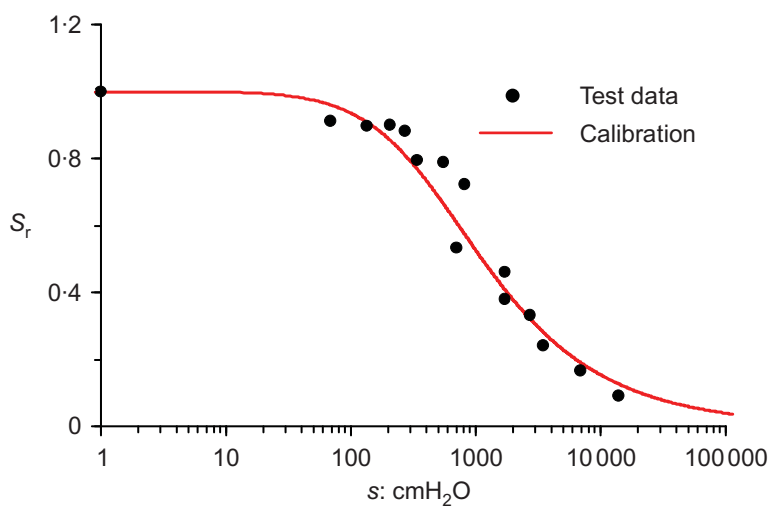

(b)

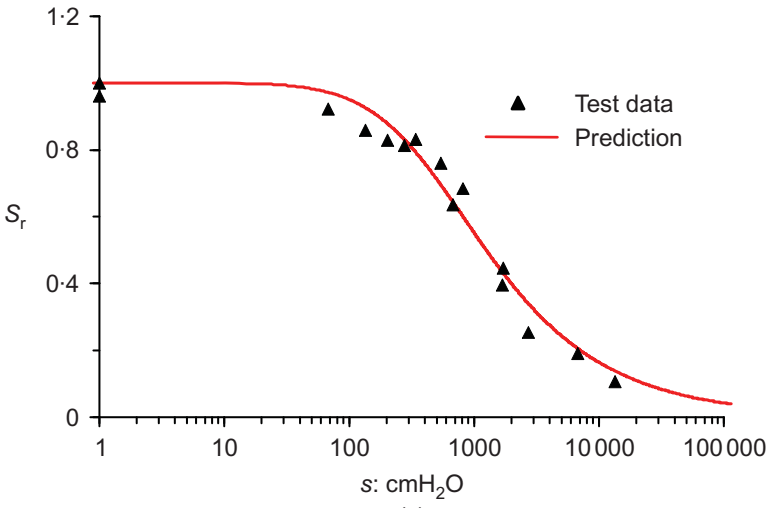

Fig. 8. Experimental results and simulations showing the $S_{\mathrm{r}}-s$ relationship for $S I$ tailings with different initial void ratios: (a) $e_{\mathrm{i}}=0.802$, calculated $s_{\mathrm{ae}}=62 \mathrm{cmH}_{2} \mathrm{O}$; (b) $e_{\mathrm{i}}=0.746$, calculated $s_{\mathrm{ae}}=80 \mathrm{cmH}_{2} \mathrm{O}$; (c) $e_{\mathrm{i}}=0.695$, calculated $s_{\mathrm{ae}}=101 \mathrm{cmH}_{2} \mathrm{O}$. Data after Aubertin et al. (1998); $a=400 \mathrm{cmH}_{2} \mathrm{O}, m=1 \cdot 2, n=0 \cdot 5$, $1 \mathrm{cmH}_{2} \mathrm{O}=0 \cdot 098 \mathrm{kPa}$

Simpson's rule is adopted as an example to show one of the possible methods to perform such an approximation. Equation (12) can be reformed and integrated as

$$
\begin{aligned}
\int_{S_{\mathrm{e}}^{\text {ref }}}^{S_{\mathrm{e}}} \frac{\mathrm{d} S_{\mathrm{e}}}{S_{\mathrm{e}}\left(1-S_{\mathrm{e}}\right)^{\xi}} & =\int_{e_{\mathrm{i}}^{\text {ref }}}^{e_{\mathrm{i}}}-\frac{\mathrm{d} e_{\mathrm{i}}}{e_{\mathrm{i}}} \\
& =\ln \frac{e_{\mathrm{i}}^{\text {ref }}}{e_{\mathrm{i}}}
\end{aligned}
$$

Applying Simpson's rule to the left-hand side of equation (22), gives

$$
\ln \frac{e_{\mathrm{i}}^{\mathrm{ref}}}{e_{\mathrm{i}}} \approx \frac{\left(S_{\mathrm{e}}-S_{\mathrm{e}}^{\mathrm{ref}}\right)}{6}\left[f\left(S_{\mathrm{e}}^{\mathrm{ref}}\right)+4 f\left(\frac{S_{\mathrm{e}}^{\mathrm{ref}}+S_{\mathrm{e}}}{2}\right)+f\left(S_{\mathrm{e}}\right)\right]
$$

where

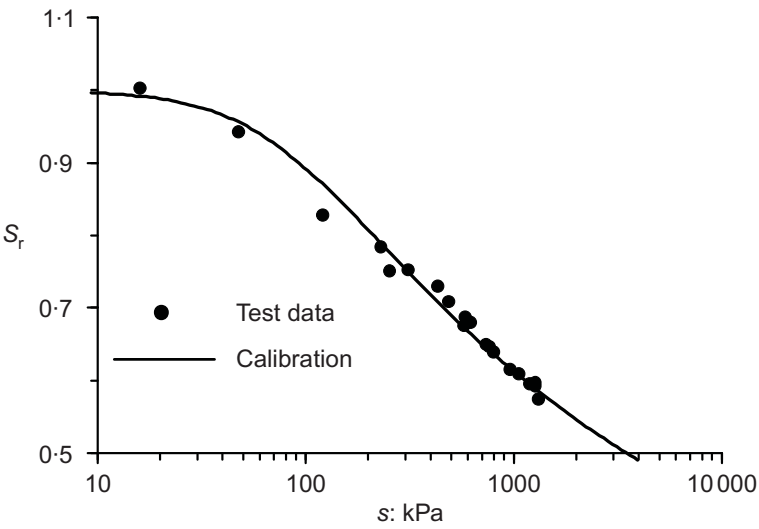

(a)

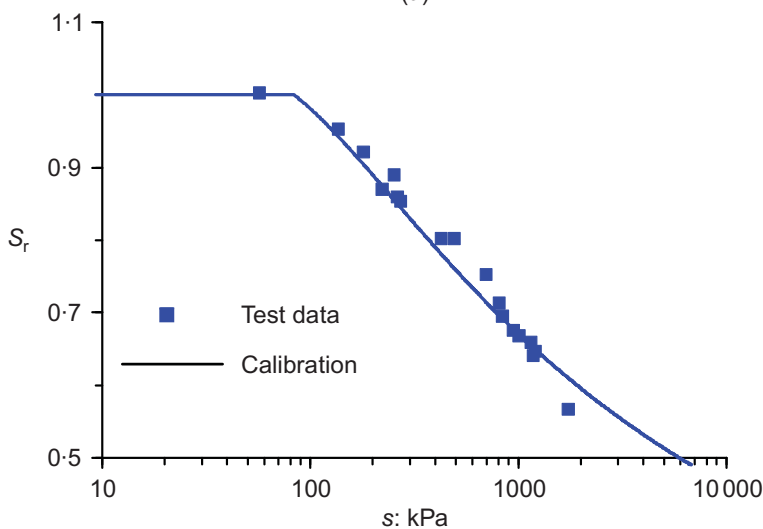

(b)

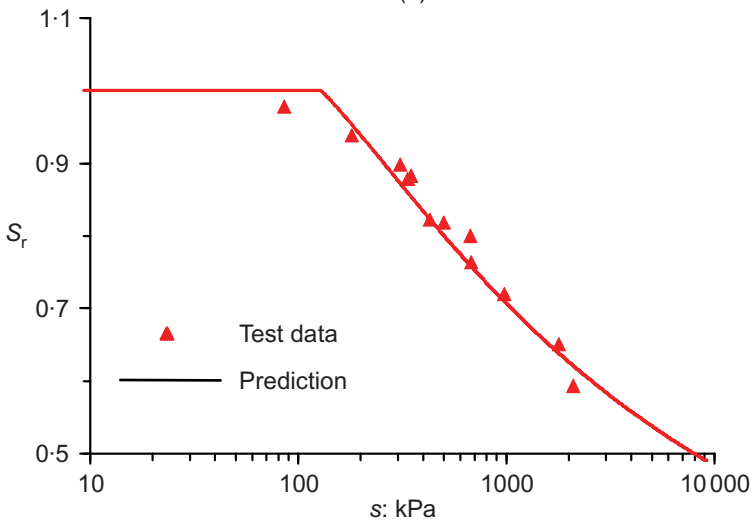

(c)

Fig. 9. Measured and predicted SWCCs of reconstituted Barcelona silt with different initial void ratios: (a) $e_{\mathrm{i}}=\mathbf{0 . 6 2}$; (b) $e_{\mathrm{i}}=0.54$; (c) $e_{\mathrm{i}}=0.50$. Data after Tarantino (2009); $a=75 \mathrm{kPa}$, $m=1 \cdot 7, n=0 \cdot 15, S_{\mathrm{r}}^{\mathrm{res}}=0 \cdot 2, \zeta=0 \cdot 05$

$$
f(x)=\frac{1}{x(1-x)^{\xi}}
$$

The accuracy of equation (23) can be investigated by comparing approximate solutions with analytical solutions in some special cases (for example, $\zeta=0 \cdot 5$ ). The parameters for the reference SWCC (van Genuchten's) are assumed as: $a=100 \mathrm{kPa}, \quad m=3 \cdot 0, \quad n=1 \cdot 0$, reference void ratio $e_{i}^{\text {ref }}=1 \cdot 6$ and initial void ratio $e_{i}=1 \cdot 2$. The suction range for this investigation is from $1 \mathrm{kPa}\left(S_{\mathrm{e}}^{\text {ref }}=1\right)$ to $1000 \mathrm{kPa}\left(S_{\mathrm{e}}^{\mathrm{ref}}=0 \cdot 001\right)$. The maximum approximation error between equation (23) and the analytical solution (i.e. equation (14)) is

$$
E R R=\max \left|S_{\mathrm{e}}^{(23)}-S_{\mathrm{e}}^{(14)}\right|=0 \cdot 001
$$

where $S_{\mathrm{e}}^{(23)}$ and $S_{\mathrm{e}}^{(14)}$ are the calculated effective degree of saturation by way of equation (23) and equation (14) respectively. The accuracy of the approximate closed-form solution (i.e. equation (23)) is usually good enough for engineering practice. 


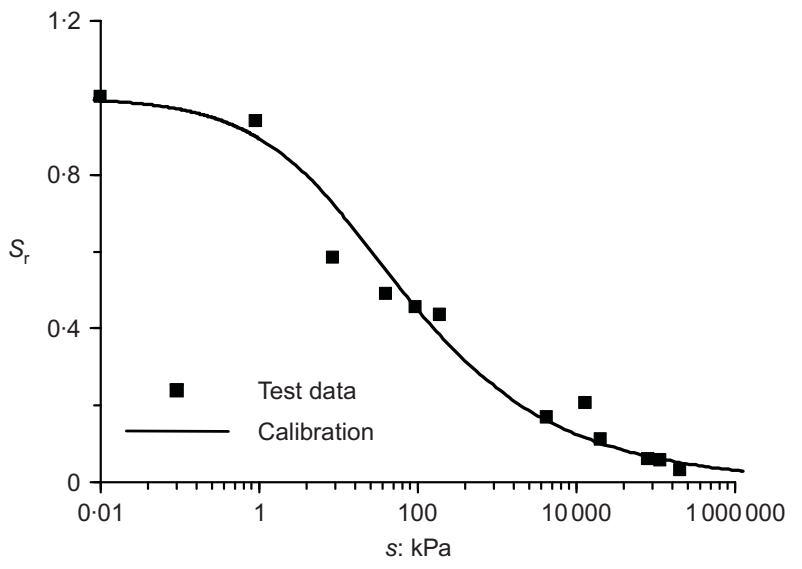

(a)

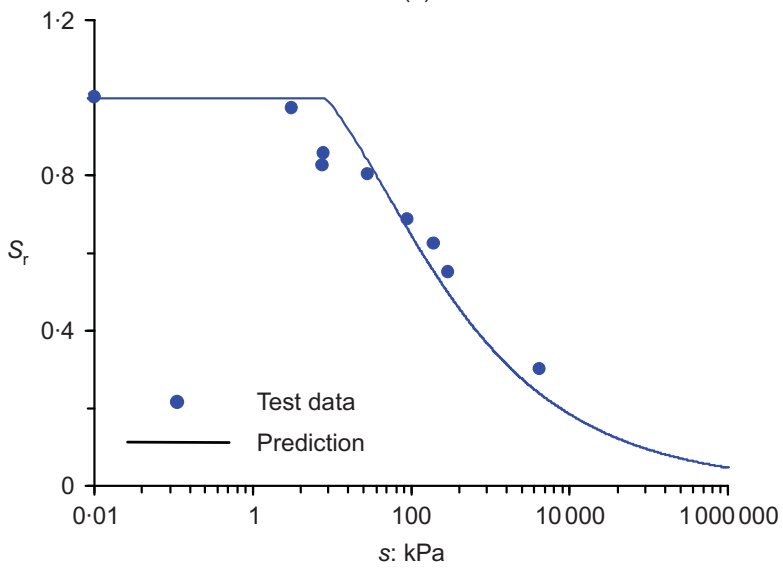

(c)

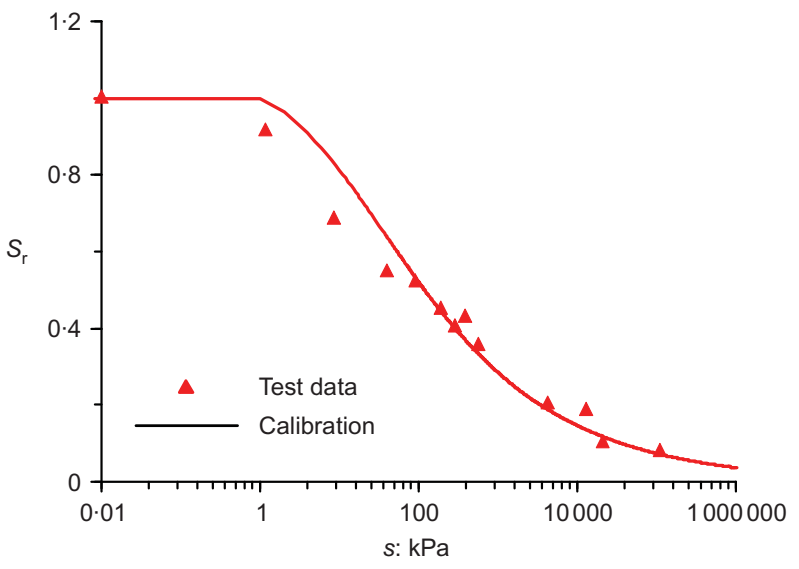

(b)

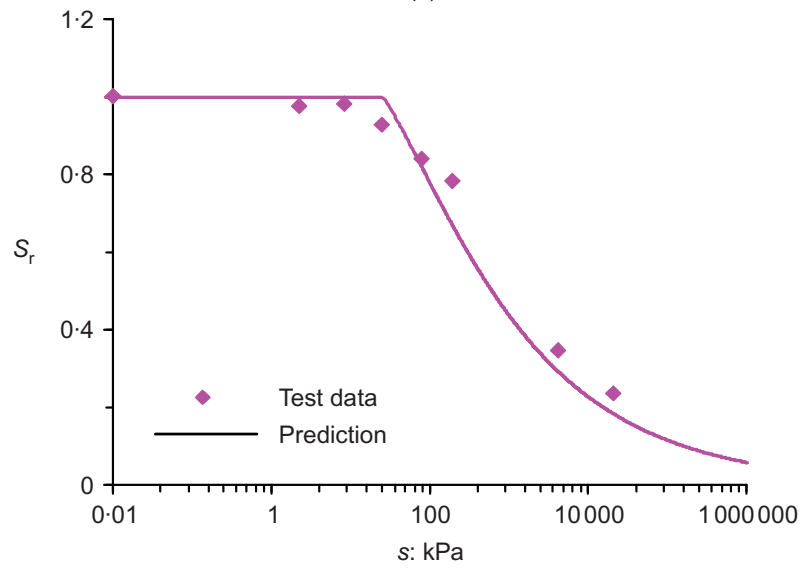

(d)

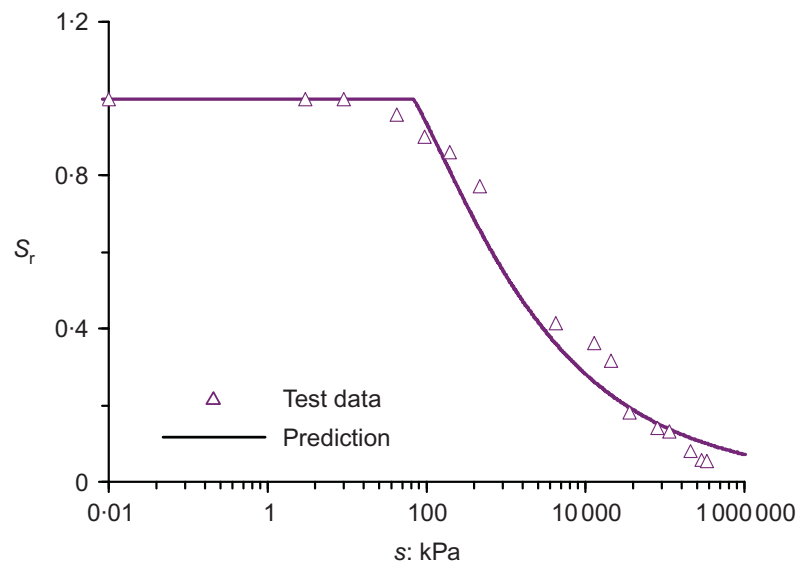

(e)

Fig. 10. Measured and predicted family of SWCCs for a clayey sand with different initial void ratios: $\left(\right.$ a) $e_{\mathrm{i}}=1 \cdot 01 ;(\mathrm{b}) e_{\mathrm{i}}=0 \cdot 86$; (c) $e_{\mathrm{i}}=0.68$; (d) $e_{\mathrm{i}}=0.55$; (e) $e_{\mathrm{i}}=0.44$. Data after Salager et al. (2010); $a=10 \mathrm{kPa}, m=0 \cdot 6, n=0.5, S_{\mathrm{r}}^{\mathrm{res}}=0, \zeta=0 \cdot 1$

\section{NOTATION}

a fitting parameter in van Genuchten's equation (van Genuchten, 1980)

$E R R$ maximum approximation error between approximate solution and analytical solution

$e$ void ratio

$e_{\mathrm{i}}$ initial void ratio

$e_{\mathrm{i}}^{\mathrm{ref}}$ reference initial void ratio

$e_{\mathrm{w}} \quad$ water ratio

$m$ fitting parameter in van Genuchten's equation (van Genuchten, 1980)

$n$ fitting parameter in van Genuchten's equation (van Genuchten, 1980)

$S_{\mathrm{e}} \quad$ effective degree of saturation

$S_{\mathrm{e}}^{\text {ref }}$ reference SWCC expressed by way of effective degree of saturation
$S_{\mathrm{r}}$ degree of saturation

$S_{\mathrm{r}}^{\mathrm{M}} \quad$ macroscopic degree of saturation

$S_{\mathrm{r}}^{\mathrm{m}} \quad$ microscopic degree of saturation

$S_{\mathrm{r}}^{\mathrm{ref}}$ reference SWCC

$S_{\mathrm{r}}^{\text {res }}$ residual degree of saturation

$s$ matric suction

$s_{\mathrm{ae}}$ air entry value

$s_{\mathrm{re}}$ residual suction in Fredlund \& Xing's SWCC equation (Fredlund \& Xing, 1994)

$V$ total volume of soil element

$V_{\text {a }}$ volume of air in a soil element

$V_{\mathrm{v}}$ volume of void in a soil element

$V_{\mathrm{w}}$ volume of water in a soil element

$V_{\mathrm{w}}^{\mathrm{M}}$ volume of water in macroscopic pores

$V_{\mathrm{w}}^{\mathrm{m}} \quad$ volume of water in microscopic pores

$v$ specific volume 
$\alpha$ fitting parameter in Fredlund \& Xing's equation (Fredlund \& Xing, 1994)

$\beta$ fitting parameter in Fredlund \& Xing's equation (Fredlund \& Xing, 1994)

$\gamma$ fitting parameter in Fredlund \& Xing's equation (Fredlund \& Xing, 1994)

$\varepsilon_{\mathrm{vi}}$ volumetric strain due to initial volume change

$\zeta$ fitting parameter that describes the effect of initial density on SWCCs

$\theta \quad$ volumetric water content

$\theta_{\mathrm{r}}$ residual volumetric water content

$\theta_{\mathrm{s}}$ volumetric water content for saturated state

$\lambda$ fitting parameter in Brooks \& Corey's equation (Brooks \& Corey, 1964)

$\xi$ proportion of volume change of macroscopic pore water in total volume change

$\phi \quad$ soil constant introduced by Gallipoli et al. (2003)

$\varphi$ soil constant introduced by Gallipoli et al. (2003)

$\phi^{\mathrm{b}}$ suction friction angle

$\chi$ weight factor for effective stress variable

$\psi \quad$ soil-water potential

\section{REFERENCES}

Alonso, E. E., Pereira, J. M., Vaunat, J. \& Olivella, S. (2010). A microstructurally based effective stress for unsaturated soils. Géotechnique 60, No. 12, 913-925, http://dx.doi.org/10.1680/ geot.8.P.002.

Arya, L. M. \& Paris, J. F. (1981). A physicoempirical model to predict the soil moisture characteristic from particle-size distribution and bulk density data. Soil Sci. Soc. Am. J. 45, No. 6, $1023-1030$.

Assouline, S. (2001). A model for soil relative hydraulic conductivity based on the water retention characteristic curve. Water Resour. Res. 37, No. 2, 265-271.

Assouline, S. (2006). Modeling the relationship between soil bulk density and the water retention curve. Vadose Zone J. 5, No. 2, $554-562$

Aubertin, M., Richard, J. F. \& Chapuis, R. P. (1998). A predictive model for the water retention curve: application to tailings from hard-rock mines. Can. Geotech. J. 35, No. 1, 55-69.

Aubertin, M., Mbonimpa, M., Bussiere, B. \& Chapuis, R. P. (2003). A model to predict the water retention curve from basic geotechnical properties. Can. Geotech. J. 40, No. 6, 1104-1122.

Brady, N. C. (1999). The nature and properties of soils, 12th edn. Upper Saddle River, NJ, USA: Prentice Hall.

Brooks, R. \& Corey, A. (1964). Hydraulic properties of porous media, Hydrology Paper No. 3. Fort Collins, CO, USA: Colorado State University.

Burger, C. A. \& Shackelford, C. D. (2001a). Evaluating dual porosity of pelletized diatomaceous earth using bimodal soilwater characteristic curve functions. Can. Geotech. J. 38, No. 1, 53-66.

Burger, C. A. \& Shackelford, C. D. (2001b). Soil-water characteristic curves and dual porosity of sand diatomaceous earth mixtures. J. Geotech. Geoenviron. Engng ASCE 127, No. 9, 790-800.

Chateau, X. \& Viet, T. B. (2010). Influence of the temperature on the water content curves: a micromechanical approach. In Unsaturated soils: Theoretical and numerical advances in unsaturated soil mechanics (eds O. Buzzi, S. Fityus and D. Sheng), pp. 849-854. Leiden, the Netherlands: CRC Press.

Croney, D. \& Coleman, J. D. (1954). Soil structure in relation to soil suction. J. Soil Sci. 5, No. 1, 75-84.

Fredlund, D. G. \& Xing, A. (1994). Equations for the soil-water characteristic curve. Can. Geotech. J. 31, No. 3, 521-532.

Fredlund, D. G., Xing, A. \& Huang, S. (1994). Predicting the permeability function for unsaturated soils using the soil-water characteristic curve. Can. Geotech. J. 31, No. 3, 521-532.

Fredlund, D. G., Xing, A., Fredlund, M. D. \& Barbour, S. L. (1996). Relationship of the unsaturated soil shear strength to the soil-water characteristic curve. Can. Geotech. J. 33, No. 3, 440448.

Gallipoli, D., Wheeler, S. J. \& Karstunen, M. (2003). Modelling of variation of degree of saturation in a deformable unsaturated soil. Géotechnique 53, No. 1, 105-112, http://dx.doi.org/ 10.1680/geot.2003.53.1.105.

Gardner, W. (1956). Mathematics of isothermal water conduction in unsaturated soils. In International symposium on physicochemical phenomenon in soils, Highway Research Board Special Report 40, pp. 78-87.Washington, DC, USA: Highway Research Board.

Haverkamp, R., Leij, F. J., Fuentes, C., Sciortino, A. \& Ross, P. J. (2005). Soil water retention: I. Introduction of a shape index. Soil Sci. Soc. Am. J. 69, No. 6, 1881-1890.

Huang, S., Barbour, S. L. \& Fredlund, D. G. (1998). Development and verification of a coefficient of permeability function for a deformable unsaturated soil. Can. Geotech. J. 35, No. 3, 411425 .

Jotisankasa, A. (2005). Collapse behaviour of a compacted silty clay, PhD thesis, Imperial College London, UK.

Khalili, N., Habte, M. A. \& Zargarbashi, S. (2008). A fully coupled flow deformation model for cyclic analysis of unsaturated soils including hydraulic and mechanical hystereses. Comput. Geotech. 35, No. 6, 872-889.

Laliberte, G. E., Corey, A. \& Brooks, R. (1966). Properties of unsaturated porous media, Hydrology Paper No. 3. Fort Collins, CO, USA: Colorado State University.

$\mathrm{Li}$, X. S. (2005). Modelling of hysteresis response for arbitrary wetting/drying paths. Comput. Geotech. 32, No. 2, 133-137.

Masin, D. (2010). Predicting the dependency of a degree of saturation on void ratio and suction using effective stress principle for unsaturated soils. Int. J. Numer. Anal. Methods Geomech. 34, No. 1, 73-90.

Mbonimpa, M., Aubertin, M., Maqsoud, A. \& Bussiere, B. (2006). Predictive model for the water retention curve of deformable clayey soils. J. Geotech. Geoenviron. Engng ASCE 132, No. 9, $1121-1132$.

Miller, G. A., Khoury, C. N., Muraleetharan, K. K., Liu, C. \& Kibbey, T. C. G. (2008). Effects of soil skeleton deformations on hysteretic soil water characteristic curves: experiments and simulations. Water Resour. Res. 44, paper W00C06.

Mualem, Y. (1976). A new model for predicting the hydraulic conductivity of unsaturated porous media. Water Resour. Res. 12, No. 3, 513-522.

Ng, C. W. W. \& Pang, Y. W. (2000). Influence of stress state on soil-water characteristics and slope stability. J. Geotech. Geoenviron. Engng ASCE 126, No. 2, 157-166.

Nuth, M. \& Laloui, L. (2008). Advances in modelling hysteretic water retention curve in deformable soils. Comput. Geotech. 35, No. 6, 835-844.

Romero, E. (1999). Characterisation and thermo-mechanical behaviour of unsaturated Boom clay: An experimental study, $\mathrm{PhD}$ thesis, UPC, Barcelona, Spain.

Romero, E., Gens, A. \& Lloret, A. (1999). Water permeability, water retention and microstructure of unsaturated compacted Boom clay. Engng Geol. 54, No. 1-2, 117-127.

Romero, E., Gens, A. \& Lloret, A. (2001). Temperature effects on the hydraulic behaviour of an unsaturated clay. Geotech. Geol. Engng 19, No. 3, 311-332.

Salager, S., Ei Youssoufi, M. S. \& Saix, C. (2010). Definition and experimental determination of a soil-water retention surface. Can. Geotech. J. 47, No. 6, 609-622.

Salager, S., Ferrari, M., Nuth, M. \& Laloui, L. (2011). Investigation on water retention behaviour of deformable soils. In Unsaturated soils (eds E. E. Alonso and A. Gens), Vol. 1, pp. 485-490. Leiden, the Netherlands: CRC Press.

Sheng, D. \& Zhou, A. N. (2011). Coupling hydraulic with mechanical models for unsaturated soils. Can. Geotech. J. 48, No. 5, $826-840$.

Sun, D. A., Sheng, D., Cui, H. B. \& Sloan, S. W. (2007). A density-dependent elastoplastic hydro-mechanical model for unsaturated compacted soils. Int. J. Numer. Analyt. Methods Geomech. 31, No. 11, 1257-1279.

Sun, D. A., Sheng, D., Xiang, L. \& Sloan, S. W. (2008). Elastoplastic prediction of hydro-mechanical behaviour of unsaturated soils under undrained conditions. Comput. Geotech. 35, No. 6, 845852 .

Tarantino, A. (2009). A water retention model for deformable soils. Géotechnique 59, No. 9, 751-762, http://dx.doi.org/10.1680/ geot.7.00118. 
Toll, D. G. \& Ong, B. H. (2003). Critical state parameters for an unsaturated residual sandy clay. Géotechnique 53, No. 1, 93103, http://dx.doi.org/10.1680/geot.2003.53.1.93.

van Genuchten, M. T. (1980). A closed-form equation for predicting the hydraulic conductivity of unsaturated soils. Soil Sci. Soc. Am. J. 44, No. 5, 892-898.

Vanapalli, S. K., Fredlund, D. G., Pufahl, D. E. \& Clifton, A. W. (1996). Model for the prediction of shear strength with respect to soil suction. Can. Geotech. J. 33, No. 3, 379-392.

Vanapalli, S. K., Fredlund, D. G. \& Pufahl, D. E. (1999). The influence of soil structure and stress history on soil-water characteristics of a compacted till. Géotechnique 49, No. 2, 143-159, http://dx.doi.org/10.1680/geot.1999.49.2.143.
Wang, Y., Wu, G., Grove, S. M. \& Anderson, M. G. (2008) Modelling water retention characteristic of unsaturated soils. Proc. 1st Eur. Conf. on Unsaturated Soils, Durham, 675-681.

Wheeler, S. J. (1996). Inclusion of specific water volume within an elasto-plastic model for unsaturated soil. Can. Geotech. J. 33, No. 1, 42-57.

Wheeler, S. J., Sharma, R. S. \& Buisson, M. S. R. (2003). Coupling of hydraulic hysteresis and stress-strain behaviour in unsaturated soils. Géotechnique 53, No. 1, 41-54, http://dx.doi.org/ 10.1680/geot.2003.53.1.41.

Zhang, L. M. \& Chen, Q. (2005). Predicting bimodal soil-water characteristic curves. J. Geotech. Geoenviron. Engng ASCE 131, No. 5, 666-670. 